\title{
TENSÕES E DISTENSÕES ENTRE A SEGURANÇA DO ESTADO-NAÇÃO E OS DIREITOS HUMANOS: SEGURANÇA HUMANA E MIGRAÇÕES INTERNACIONAIS SOB O OLHAR DA TEORIA DOS DIREITOS FUNDAMENTAIS DE ROBERT ALEXY
}

\section{TENSIONES Y DISTENSIONES ENTRE LA SEGURIDAD DEL ESTADO-NACIÓN Y LOS DERECHOS HUMANOS: SEGURIDAD HUMANA Y MIGRACIONES INTERNACIONALES BAJO LA MIRADA DE LA TEORÍA DE LOS DERECHOS FUNDAMENTALES DE ROBERT ALEXY}

${ }^{1}$ Rickson Rios Figueira

\section{RESUMO}

O presente artigo objetiva analisar as relações entre as abordagens tradicionais dos discursos de segurança do Estado-nação, o conceito e aplicação da segurança humana e o quadro normativo de direitos humanos estabelecido no âmbito das Nações Unidas, após a 2a Guerra Mundial. Tanto a securitização, quanto a segurança humana e as normas de direitos humanos importam no tratamento do estrangeiro imigrante, em particular, o refugiado. Entretanto, após o 11 de setembro, o tema da imigração vem sendo securitizado como ameaçador. Em busca do restabelecimento do equilíbrio entre a segurança de Estado e as normas e valores de proteção humana, utiliza-se no presente artigo o quadro teórico proposto por Robert Alexy sobre os direitos fundamentais, aplicando-o ao princípio da dignidade da pessoa humana, basilar no diálogo entre os conceitos de segurança humana e direitos humanos.

Palavras-chave: Segurança internacional, Segurança humana, Direitos humanos, Direito dos refugiados, Dignidade humana

\section{RESUMEN}

El presente artículo objetiva analisar las relaciones entre los abordajes tradicionales de los discursos de seguridad del Estado-nación, el concepto y aplicación de la seguridad humana y el cuadro normativo de derechos humanos establecido en el ámbito de las Naciones Unidas, después de la 2a Guerra Mundial. Tanto la securitización, cuanto la seguridad humana y las normas de derechos humanos importan en el tratamiento del extranjero inmigrante, en particular, el refugiado. Sin embargo, después del 11 de septiembre, el tema de la inmigración ha estado securitizado como una amenaza. En busca del restablecimiento del equilibrio entre la seguridad del Estado y las normas y valores de protección humana, se utiliza en el presente artículo el cuadro teórico propuesto por Robert Alexy sobre los derechos fundamentales, aplicando al principio de la dignidad de la persona humana, basilar en el dialogo entre los conceptos de seguridad humana y derechos humanos.

Palabras-claves: Seguridad internacional, Seguridad humana, derechos humanos, Derechos de los refugiados, Dignidad humana

\footnotetext{
${ }^{1}$ Dourando em Sociologia e Direito pela Universidade Federal Fluminense - UFF, Rio de Janeiro (Brasil). Professor pela Universidade Federal Rural do Rio de Janeiro - UFRRJ, Rio de Janeiro (Brasil). E-mail: ricksonrios@gmail.com
} 


\section{Introdução}

Nos últimos anos, o tema da imigração vem sendo tratado pelos Estados como relacionado à (in)segurança das sociedades receptoras. As ações de contenção do fluxo migratório, adotadas pelos governos dos Estados de destino de migrantes - principalmente os Estados desenvolvidos do Ocidente - são reiteradamente noticiadas, algumas delas gestionadas de maneira violenta ou, ao menos, despreocupada com a condição humana do imigrante, principalmente nas situações de solicitação de refúgio. Medidas como a construção de centros de internação de imigrantes, criminalização da imigração irregular e a construção de muros têm bastante visibilidade. Outras ações de contenção, mais discretas, vem sendo adotadas pelos Estados destinatários, como a alocação de agentes de imigração em aeroportos do mundo, de onde partem os estrangeiros, para evitar que cheguem a embarcar para seu destino (Canadá), ou a limitação da aplicação territorial da Convenção de Genebra sobre Refugiados (1951), impedindo que o estrangeiro se valha do princípio do non refoulement, ainda que já se encontre em território do Estado (Austrália).

Alega-se, para justificar tais medidas, um leque de razões, principalmente de natureza econômica, de bem-estar social da sociedade de acolhida e de segurança. O presente artigo tem por objetivo analisar as relações entre o tradicional discurso de segurança do Estado, a construção mais recente de um discurso de segurança humana, no âmbito das Nações Unidas, e o Direito dos Refugiados - articulado a um quadro mais amplo de Direitos Humanos e Fundamentais, em sua dimensões internacional e nacional. Para isso, utilizarei aqui o quadro teórico de direitos fundamentais proposto por Robert Alexy, a partir do qual situo no princípio da dignidade da pessoa humana o fundamento para a adoção de uma abordagem de segurança que tenha por objeto os indivíduos de uma sociedade e não o Estado, e que possa ser aplicada ao imigrante e, em particular, ao refugiado.

O artigo se divide em três partes: (1) apresentação das principais características e teorias que tratam da segurança de Estado e da segurança humana; (2) as relações entre os direitos humanos e a segurança humana; e (3) os regimes de proteção aos direitos dos refugiados e a possível utilização do princípio da dignidade humana como fator de mediação ante as exigências estatais de segurança.

\section{Entre a Segurança do Estado e a Segurança Humana}

\subsection{Segurança e Relações Internacionais}

Os Estados têm ao seu alcance um leque de abordagens teóricas que lhes permitem um conjunto variado de opções racionais acerca de sua segurança. Os diferentes pressupostos 
teóricos possibilitam análises com resultados bastante distintos sobre o grau de ameaça que um estrangeiro pode significar para uma soberania. As teorias Realista, Liberal e Construtivista oferecem diferentes e importantes parâmetros para a definição da segurança dos Estados.

O núcleo normativo da teoria realista é a segurança nacional e a sobrevivência do Estado, cuja existência é essencial para o bem estar de seus cidadãos. A sociedade humana e a moralidade existem confinados no Estado, fora do qual o ambiente é perigoso e caracterizado por conflitos. Os outros Estados não são considerados confiáveis, de sorte que as convenções e tratados internacionais seriam arranjos provisórios e condicionados ao interesse nacional (JACKSON \& SØRENSEN, 2003, pp. 68-70).

Os realistas acreditam que a política internacional se caracteriza por uma anarquia internacional. As relações internacionais são primariamente baseadas nas relações entre os Estados. Os outros atores internacionais - indivíduos, organizações internacionais, organizações não-governamentais etc - são menos importantes ou irrelevantes.

A teoria liberal, por sua vez, apresenta concepções sobre segurança que, tal qual o Realismo, tem por objeto a segurança do Estado-nação. No entanto, entende como importante para a promoção dos interesses do Estado os acordos multilaterais. Ademais, reconhece um claro processo de desterritorialização, com a participação de uma pluralidade de atores internacionais não estatais (ONGs, corporações internacionais, indivíduos etc) como agentes que influenciam a agenda de segurança dos Estados.

Os teóricos do Liberalismo creem que, além da segurança dos Estados, importam também temas econômicos, sociais e culturais. A interdependência entre atores internacionais faz com que a cooperação entre eles e o respeito ao direito ofereçam uma oportunidade para alcançar e manter a segurança (EDWARDS \& FERSTMAN, 2009, p. 10). Uma perspectiva de globalização liberal está atenta a como atores internacionais securitizam temas específicos, como os fluxos financeiros, o terrorismo, a liberalização do comércio, o meio ambiente, as migrações etc (BUZAN, 2002, p. 238).

Os construtivistas, de sua parte, creem que não existe uma realidade objetiva, mas uma construção intersubjetiva da realidade. Seu foco está nas interações sociais. Assim, o sistema internacional é algo criado pelos humanos, não algo físico e real. Trata-se de um corpo de pensamento, feito de regras e ideias de um grupo determinado de pessoas, constituídas em certo tempo e lugar, mas que podem mudar.

As ideias, segundo o Construtivismo, podem sedimentar-se de maneira durável, como é o caso da ideia de soberania. Entretanto, como se trata de uma construção social, pode 
passar por processos de renegociação e mudar seu conteúdo. A soberania hoje tem sentido distinto da visão prevalente ao tempo do tratado de Vestfália.

O Construtivismo oferece não uma visão de como é o mundo, mas uma metodologia de questionamento e análise de discursos utilizados para interpretar o mundo. As ameaças à segurança são determinadas por meio de um conjunto de discursos que, na perspectiva construtivista, devem ser analisados e decodificados para sua melhor compreensão (BUZAN, 2002, p. 242).

Desde o fim da Guerra Fria até hoje houve uma mudança no discurso de segurança. No contexto da bipolarização da Guerra Fria, a ameaça à segurança de um Estado vinha principalmente do poder material e militar dos Estados do polo opositor.

A mudança de estrutura do sistema internacional, que, depois de 1991, passa a contar com uma só superpotência, gerou uma resposta interpretativa realista de reorganização dos Estados em grandes blocos, para reequilibrar o poder no mundo. Os liberais ressaltaram a crescente importância dos arranjos multilaterais, que poderiam constranger e limitar as ações da superpotência em razão das normas de direito internacional. Isso, no entanto, dependeria do aceite e submissão dos EUA às regras das organizações internacionais, o que nem sempre aconteceu (EDWARDS \& FERSTMAN, 2009, p. 14).

Muitos dos desafios da era Pós-Guerra Fria, no entanto, não podiam ser solucionados pela abordagem realista tradicional. Tratava-se de uma série de ameaças que ultrapassavam fronteiras, como desastres ambientais, conflitos armados internos, pobreza, terrorismo internacional etc.

Depois do 11 de setembro de 2001, a significativa ameaça que grupos não estatais poderiam impor à integridade territorial de Estados promove uma reação de Estados por meio do aumento do militarismo e da adoção de medidas unilaterais. Nesse contexto, reiteradas violações do direito, como a invasão ao Iraque ou a manutenção de prisioneiros em Guantânamo, foram comuns nos últimos doze anos, que, ademais, são marcados por uma profunda crise econômica mundial desde 2008.

Esses eventos representaram um marco para o estudo da Segurança Internacional. As ameaças representadas por grupos não-Estatais provenientes de outro Estado tiveram consequências para a relação entre o "Ocidente e o resto do mundo"1, que passou a ser a questão organizadora da segurança internacional (BUZAN \& HANSEN, 2009, p. 226).

\footnotetext{
${ }^{1}$ The West and the rest.
} 


\subsection{Os Estudos de Segurança}

Os estudos de segurança internacional desenvolveram-se principalmente nos Estados Unidos, Europa e Austrália, como um campo, de início, independente. Todavia, foi rapidamente absorvido pelos estudos de Relações Internacionais. Antes da II Guerra Mundial, a literatura produzida sobre o tema relacionava-se a aspectos militares, estratégicos e de geopolítica. Autores como Clausewitz, Mahan e Haushofer tiveram grande destaque nessa época. Após 1945, os estudos de segurança passaram a compreender um espectro mais amplo de preocupações, como a importância da coesão social para a segurança, a relação entre ameaças militares e não-militares, o impacto das armas nucleares na segurança de um Estado etc (BUZAN \& HANSEN, 2009, p. 1-2).

\subsubsection{A Escola de Copenhague}

As condições para o alargamento da agenda de segurança e o fortalecimento de outras teorias de segurança internacional para além do pensamento realista surgiram com o fim da Guerra Fria. ${ }^{2}$ As novas abordagens ficaram conhecidas como estudos não tradicionais de segurança. Dentre elas estão os Estudos para a $\mathrm{Paz}^{3}$, que surgem após a Primeira Guerra Mundial, embora consolidem-se como disciplina somente entre as décadas de 1950 e 1960, com a criação do Peace Research Institute Oslo (PRIO). A mudança dos Estudos Estratégicos para os Estudos para a Paz ampliou seu objeto, que deixa de ser a guerra, para incorporar qualquer forma de violência (BOULDING, 2000, p. 4).

Uma das grandes referências atuais nos temas de Segurança Internacional é o Copenhagen Peace Research Institute (COPRI), que também se propõe a desenvolver os estudos para a paz. Esse ficou conhecido como Escola de Copenhague e possui como principais autores Barry Buzan, Ole Wæver e Jaap de Wilde.

A Escola de Copenhague busca entender como certos temas assumem tamanha importância de modo a fazerem parte da agenda de segurança dos Estados. Para isso, os autores se utilizam da abordagem construtivista (BUZAN, WÆVER \& DE WILDE, 1998, p.

19). ${ }^{4}$ A principal contribuição da Escola de Copenhague para os estudos de segurança é a elaboração do "conceito de securitização", que será abordado a seguir. ${ }^{5}$

\footnotetext{
${ }^{2}$ Os estudos tradicionais de segurança são associados à teoria Realista, onde o objeto de estudo é o uso pelos Estados das forças militares. Os estudos não tradicionais de segurança não só compreendem o estudo estratégico- militar, mas incorporam à sua análise da segurança temas como o meio ambiente, as questões culturais e sociais, os indivíduos etc. ${ }^{3}$ Em inglês, no original, Peace Studies. ${ }^{4}$ O Construtivismo propõe que não existe uma realidade objetiva, mas uma construção intersubjetiva da realidade. Seu foco está nas interações sociais. Desse modo, o sistema internacional é algo criado pelos humanos, não algo físico e real. Trata-se de um corpo de pensamento, feito de regras e ideias de um grupo determinado de pessoas, constituídas em certo tempo e lugar, mas que podem mudar. As ideias, segundo o
} 


\subsubsection{O processo de securitização}

Para a Escola de Copenhague, segurança é a ausência de algo que possa vir a ameaçar a existência do ator no ambiente social. Uma ameaça, entretanto, resulta antes de uma construção política (BUZAN, 1997, p. 20-1). Para Wæver (1995, p. 46), a segurança representa um discurso definidor de uma ameaça à sobrevivência.

Buzan, Wæver e Wilde (1998, p. 23) explicam que qualquer questão pode transitar entre as esferas pública, privada e de segurança. O enquadramento do assunto em um dos três âmbitos é feito de acordo com as circunstâncias. Os autores ainda entendem que não é possível a implementação do processo de securitização de forma objetiva, pois é difícil medir se a questão é de fato uma ameaça, já que as relações e, portanto, as condições, são socialmente construídas. Dessa forma, a transformação de um tema em uma questão de segurança compõese de ações que ocorrem intersubjetivamente (BUZAN, W FVER \& DE WILDE, 1998, p. 30).

Primeiramente, para que o processo de securitização ocorra, o ator deve transmitir a sua preocupação a um público alvo, de modo a mostrar que algo representa uma ameaça a um objeto referente. Esse discurso visa a obter a aprovação pública para a adoção de medidas extraordinárias (EMMERS, 2007, p. 133).

Assim, o processo de securitização acontece em duas etapas: A primeira consiste na qualificação de alguma questão, pessoa ou entidade como uma ameaça para certos objetos. Não são apenas atores estatais que podem reportar ameaças. Outras entidades sociais igualmente podem fazê-lo. A segunda etapa se passa apenas quando a primeira houver sido exitosa. Consiste na imposição de medidas extraordinárias, que estão para além do domínio político (EMMERS, 2007, p. 133-4). Caso a securitização não seja bem sucedida, o tema não passará da esfera de que provém (pública ou privada) para a agenda de segurança.

Portanto, o elemento fundamental para que o processo de securitização tenha sucesso é o discurso, já que é por ele que é construída a ameaça. Questões podem ser incorporadas ou removidas da agenda de segurança apenas pelo discurso, independente de desempenharem de fato uma ameaça existencial ou não (EMMERS, 2007, p.134). Esse discurso, para obter

Construtivismo, podem sedimentar-se de maneira durável, como é o caso da ideia de soberania. Mas, como se trata de uma construção social, pode passar por processos de renegociação e trocar de conteúdo. O Construtivismo não nos oferece uma visão de como é o mundo, mas, sim, uma metodologia de questionamento e análise de discursos utilizados para interpretar o mundo. As ameaças à segurança são determinadas por meio de um conjunto de discursos, que, na perspectiva construtivista, devem ser analisados e decodificados para sua melhor compreensão (BUZAN, 2002, p. 242).

${ }^{5}$ Além do conceito de securitização, a Escola de Copenhague traz para o estudo da segurança uma abordagem multissetorial e novas unidades de análise. 
sucesso, deve atender a três condições: (1) existência de ameaças; (2) exigência de ação emergencial; e (3) efeitos nas relações entre unidades envolvidas, de modo a liberá-las das regras concernentes à determinadas questões relacionadas ao tema a que se refere o discurso (BUZAN, W ÆVER \& DE WILDE, 1998, p. 26).

Assim como a securitização significa a inclusão de um assunto, através da prática discursiva, na agenda de segurança, há também o processo de "dessecuritização", que consiste no fluxo oposto: a questão, também por meio da estratégia da retórica, deixa de ser um tema emergencial para voltar a se enquadrar em uma das duas outras esferas (pública ou privada) (BUZAN, WÆVER \& DE WILDE, 1998, p.4).

Compreender o processo de securitização importa ao presente trabalho pela politização e introdução do tema das migrações, por meio de discursos, na agenda de segurança dos Estados.

\subsection{A Segurança Humana}

O conceito de "segurança humana foi utilizado primeiramente em 1994, em um informe sobre desenvolvimento humano do Programa das Nações Unidas para o Desenvolvimento (PNUD), segundo Paris (2001, p. 89). No ano 2000, durante o Encontro do Milênio das Nações Unidas, o consenso quanto à importância da liberdade em relação à necessidade (freedom from want) e da liberdade do medo (freedom from fear) abriu caminho para que se instituísse a Comissão sobre Segurança Humana. Em 2003, a Comissão publicou o informe "Human Security Now", de onde se extraem as noções fundamentais sobre o conceito de segurança humana:

(...) proteger o centro vital de todas as vidas humanas de modo a melhorar as liberdades e a realização humana. A segurança humana significa a proteção das liberdades fundamentais - liberdades que são a essência da vida. Ela significa proteger as pessoas de ameaças e situações críticas (severas) e penetrantes (estendidas). Significa usar os processos que criam as forças e aspirações das pessoas. Significa criar sistemas políticos, sociais, ambientais, econômicos, militares e culturas que juntos dão às pessoas as condições para sobrevivência, sustento e dignidade (COMMISSION ON HUMAN SECURITY, 2003, p. 4).

O informe enfatiza a complementariedade entre a segurança do Estado e a segurança humana em quatro aspectos: (1) a segurança humana é antes concernente ao indivíduo e à comunidade que ao Estado; (2) algumas das ameaças à segurança das pessoas não são classificadas como ameaças à segurança do Estado; (3) outros atores, além do Estado, devem ser considerados para se alcançar a segurança humana; e (4) a segurança humana não está relacionada somente à proteção às pessoas, mas também a dar-lhes condições de exercer a autoproteção (COMMISSION ON HUMAN SECURITY, 2003, p. 4). 
De acordo com o citado informe do PNUD, a segurança humana tem certos componentes, que podem ser assim sistematizados:

\begin{tabular}{|c|c|}
\hline \multicolumn{2}{|c|}{ Componentes da Segurança Humana } \\
\hline Componentes & Noção \\
\hline Segurança Econômica & $\begin{array}{l}\text { Pressupõe ingressos mínimos, provenientes do trabalho ou de uma rede } \\
\text { de proteção social. }\end{array}$ \\
\hline Segurança Alimentar & $\begin{array}{l}\text { Significa não somente a disponibilidade de alimento suficiente para } \\
\text { que um povo possa viver, mas que as pessoas tenham efetivo acesso ao } \\
\text { alimento, cultivando, comprando ou recebendo de algum sistema } \\
\text { público de distribuição. }\end{array}$ \\
\hline Segurança da saúde & $\begin{array}{l}\text { É afetada por enfermidades parasitarias e infecciosas, frequentemente } \\
\text { relacionadas à pobreza. A segurança da saúde compreende o acesso a } \\
\text { serviços de saúde. }\end{array}$ \\
\hline Segurança do meio ambiente & $\begin{array}{l}\text { É afetada pelos danos infligidos pela industrialização intensiva e o } \\
\text { rápido crescimento das populações, com efeitos nocivos da poluição da } \\
\text { água, da terra e do ar. }\end{array}$ \\
\hline Segurança pessoal & $\begin{array}{l}\text { Trata-se da segurança contra a violência física característica da tortura, } \\
\text { guerras, tenções étnicas, crimes ou contra violências infligidas em } \\
\text { circunstâncias específicas, como o estupro e a violência doméstica } \\
\text { (contra as mulheres), o abuso (contra crianças) ou o suicídio e o uso de } \\
\text { narcóticos (contra si mesmo). }\end{array}$ \\
\hline Segurança da comunidade & $\begin{array}{l}\text { A segurança de um pode ser ameaçada por certas práticas tradicionais } \\
\text { do grupo ao que pertence (como a servidão, a escravidão, o tratamento } \\
\text { discriminatório dirigido à mulher, práticas de mutilação genital } \\
\text { feminina etc), pelos embates entre grupos étnicos rivais ou pela } \\
\text { redução da população indicativa de sua extinção. }\end{array}$ \\
\hline Segurança política & $\begin{array}{l}\text { É a segurança que um tem em razão do respeito dos direitos humanos } \\
\text { pelo Estado. As ameaças respectivas são decorrentes da repressão do } \\
\text { Estado contra indivíduos e grupos. }\end{array}$ \\
\hline
\end{tabular}

Fonte: ${ }^{6}$

A segurança humana propõe um quadro alternativo às teorias tradicionais de segurança, que pode ser útil na preservação da dignidade e segurança dos cidadãos em determinado país.

No ano 2000, chefes de Estado e de governo de 191 países aprovaram um documento denominado We the Peoples: The Role of the United Nations in the Twenty-First Century ou, como é mais conhecido, Declaração do Milênio das Nações Unidas. O documento marcava o compromisso dessas nações de reduzir a pobreza extrema e definir objetivos que devem ser cumpridos até o ano de 2015 e são comumente denominados de Metas de Desenvolvimento do Milênio (ONU, 2000).

O conceito de segurança humana fornece uma valiosa definição para a discussão da agenda das Metas de Desenvolvimento do Milênio. A análise de Segurança Humana coloca o indivíduo, e não o Estado, como central para a definição das ações necessárias para o aumento

${ }^{6}$ ONU (PNUD), 1994, pp. 25-32. 
da segurança. Além disso, essa noção está largamente relacionada com a busca pelo desenvolvimento social e econômico.

As Metas de Desenvolvimento do Milênio, definidas pela ONU, colocam a luta contra a pobreza extrema no topo das prioridades da comunidade internacional. E a solução desse problema é fundamental para que a segurança humana seja alcançada.

\subsection{A Segurança dos Estados e os não-cidadãos}

A percepção sobre o não cidadão resulta do discurso sobre segurança assumidos pelos atores sociais. As horrendas práticas adotadas pelos nazistas na Segunda Guerra Mundial criaram uma comoção sobre a qual se erigiu o sistema jurídico internacional de proteção de asilados. Nos anos seguintes à Segunda Guerra, já instaurada a Guerra Fria, asilados e refugiados eram importantes no contexto geopolítico, já que eram a prova concreta de que o processo emigratório dos países do bloco opositor era justificável (BETTS \& LOESCHER, 2011, p. 9).

Nos anos 1990, depois da Guerra Fria, os conflitos passaram de internacionais a internos. A crescente migração em direção aos países do norte passou a ser percebida como uma ameaça às fronteiras nacionais, além de ser associada aos fluxos de criminosos e terroristas, com claras consequências para a paz e segurança internacionais (BETTS \& LOESCHER, 2011, p. 9$10)$.

A Declaração dos Estados partes da Convenção de Genebra de 1951 e do Protocolo de 1967 reconhece:

[The] complex features of the evolving environment in which refugee protection has to be provided, including the nature of armed conflict, ongoing violations of human rights and international humanitarian law, current patterns of displacement, mixed population flows, the high costs of hosting large numbers of refugees and asylumseekers and of maintaining asylum systems, the growth of associated trafficking and smuggling of persons, the problems of safeguarding asylum systems against abuse and of excluding and returning those not entitled to or in need of international protection, as well as the lack of resolution of long-standing refugee situations (...) (ACNUR, 2001).

O aumento da complexidade dos deslocamentos forçados nos anos 1990 foi identificado pela Agência das Nações Unidas para os Refugiados (ACNUR), no documento "State of the World's Refugees 1997: A Humanitarian Agenda" (ACNUR, 1997). Com os eventos de 11 de setembro, o tema das migrações ascendeu a um nível mais alto de prioridade nas políticas de segurança dos Estados. Migrantes sem documentos, refugiados, solicitantes de asilo e apátridas passaram a ser objeto de políticas governamentais de contenção das migrações. 
Nesse contexto, alguns estudos acadêmicos passaram a buscar uma relação entre migrações e terrorismo nos países ocidentais. Um exemplo de trabalho desse gênero foi publicado por Leiken e Brooke (2006), em busca de relações entre terrorismo e migração. O artigo tem como objeto o terrorismo global em direção aos países do Ocidente, entre 1993 e 2004 e investigou os dados biográficos de 373 terroristas. Os resultados das investigações indicaram o seguinte:

\begin{tabular}{|l|c|}
\hline \multicolumn{1}{|c|}{ Países de Origem } & Porcentagem de um total de 373 terroristas \\
\hline União Europeia e EUA & $41 \%$ \\
\hline Países do Magreb (Norte de África) & $36 \%$ \\
\hline $\begin{array}{l}\text { Núcleo Árabe (Egito, Iraque, Jordânia, Síria, Israel, } \\
\text { Líbano, países da península árabe e territórios } \\
\text { ocupados) }\end{array}$ & $17 \%$ \\
\hline Ásia do Sul (Malásia, Indonésia, Índia y Paquistão) & $3 \%$ \\
\hline Outros & $3 \%$ \\
\hline \multicolumn{1}{|c|}{ Fonte $^{7}$} & \\
\hline
\end{tabular}

Ademais, o citado estudo também trata do mecanismo migratório utilizado por terroristas. O trabalho identificou a maneira utilizada por 55\% dos 373 terroristas para ingressar no país em que cometeriam os atentados. Assim, os 206 terroristas utilizaram os seguintes recursos de migração:

\begin{tabular}{|l|c|}
\hline \multicolumn{1}{|c|}{ Forma de entrada no país } & Porcentagem de um total de 206 terroristas \\
\hline $\begin{array}{l}\text { Visados (principalmente de turismo e estudo, } \\
\text { seguidos do green card e de visados de negócios) }\end{array}$ & $33 \%$ \\
\hline Solicitação de Asilo ou Refúgio & $23 \%$ \\
\hline Entrada irregular & $6 \%$ \\
\hline $\begin{array}{l}\text { Nacionais europeus que ingressaram em outro país } \\
\text { europeu, segundo as regras do tratado de Schengen, } \\
\text { com autorização de entrada nos EUA com dispensa } \\
\text { de visto. }\end{array}$ & $38 \%$ \\
\hline
\end{tabular}

Fonte $^{8}$

No contexto da guerra contra o terror, o Conselho de Segurança, por meio da Resolução 1373, determina que os Estados devem:
Velar, em conformidade com o direito internacional, para que o estatuto de refugiado não seja utilizada de modo ilegítimo por autores, organizadores ou patrocinadores de atos de terrorismo, e para que não se reconheça a reivindicação de motivações políticas como causa para denegar as solicitações de extradição de supostos terroristas (ONU, 2001).

O clima de medo e a adoção de ações de combate ao terrorismo foram as justificativas assumidas para a aplicação de medidas mais duras para os refugiados e solicitantes de asilo. Segundo Goodwin-Gill:

\footnotetext{
${ }^{7}$ Planilha feita pelo autor com base nos dados retirados de LEIKEN \& BROOKE, 2006, pp. 507-508.

${ }^{8}$ Planilha feita pelo autor com base nos dados retirados de LEIKEN \& BROOKE, 2006, pp. 510-511.
} 
(...) the already restrictive, hostile and generally repressive measures which States were already taking towards refugees and asylum seekers - such as mandatory detention, denial of support, denial of access to procedures, to legal advice and representation and to appeals, and government-to-government agreements on removals-have been given spurious justification by the terrorism agenda. For some States, (or rather, for some governments), that has been the opportunity to introduce yet more stringent laws and policies, often in the aftermath of a terrorist incident, but also generally under a carefully constructed cloud of fear (GOODWIN-GILL,

2008, P.7).

O discurso de segurança dos Estados não toma em conta o bem estar dos não cidadãos e, muitas vezes, restringe seu acesso a direitos. Os paradigmas teóricos tradicionais de segurança têm como foco a segurança do Estado e de seus nacionais. Os não cidadãos, ao menos os que se encontram em situação irregular, assim permanecem, não se lhes garantindo dignidade.

\section{A relação entre Direitos Humanos e Segurança Humana}

Direitos humanos e segurança humana são conceitos semelhantes, mas não idênticos. Não há dúvida de que compartilham objetivos, tais como o fato de que o indivíduo se situa, para ambos, como centros de suas preocupações, buscando-lhes mais amplos benefícios. Direitos humanos, entretanto, representam um quadro legal definido, expresso sob a forma de soft e hard law, passeado em declarações, cartas e tratados internacionais. Segurança humana, embora coincida com os direitos humanos em diversos aspectos, tem um escopo mais amplo de preocupações, tais como as ameaças decorrentes de terremotos, crises econômicas, pandemias etc. Além disso, a segurança humana enfatiza a importância da prevenção e identifica fontes de ameaças na pobreza e na escassez. A adoção de uma abordagem baseada na segurança humana pode ser útil para apontar dimensões sobre as quais os direitos humanos deveriam se desenvolver.

O conceito que pode ser encontrado na base dos direitos humanos e da segurança humana é o de dignidade humana. De acordo com Landman (2006, p. 14):

\footnotetext{
By lowering the level of analysis to individuals and combining it with the notions of fear and want, the concept of human security shifts attention to the threats to human integrity and the conditions under which the promotion of human dignity is made possible. (...) The promotion of human dignity means that individuals have access to basic levels of food, shelter, education and health and that with such access they are capable of exercising personal autonomy, control over their own lives, and participation in the public sphere. (grifo nosso).
}

O princípio da dignidade da pessoa humana é o elemento que permite a comunicação entre os valores que orientam a segurança humana e as normas positivadas de direitos humanos. O princípio apresenta a vantagem de estar positivado no ordenamento de vários Estados (previsto, inclusive, na Constituição Brasileira), o que o torna mais operativo que o conceito de segurança humana. Todavia, o conteúdo jurídico do princípio pode ir além das 
normas positivadas de direitos humanos, avançando sobre os valores concernentes à segurança humana. Essa operação pode ser explicada pela teoria dos direitos fundamentais de Alexy.

\title{
3.1 A Teoria de Direitos Fundamentais de Alexy e sua contribuição para a questão normativa da relação entre os direitos humanos e a segurança humana
}

De acordo com Alexy (1993, p. 85-6), as normas jurídicas podem se estruturar em regras ou princípios, que são diferentes qualitativamente. $\mathrm{O}$ autor assevera que:

\begin{abstract}
(...) los principios son normas que ordenan que algo sea realizado en la mayor medida posible, dentro de las posibilidades jurídicas y reales existentes. Por lo tanto, los principios son mandatos de optimización que están caracterizados por el hecho de que pueden ser cumplidos en diferente grado y que la medida debida de su cumplimiento no sólo depende de las posibilidades reales sino también de las jurídicas. (...) En cambio, las reglas son normas que sólo pueden ser cumplidas o no. Si una regla es válida, entonces de hacerse exactamente lo que ella exige, ni más ni menos. Por lo tanto, las reglas contienen determinaciones en el ámbito de lo fáctica y jurídicamente posible. Esto significa que la diferencia entre reglas y principios es cualitativa y o de grado. Toda norma es o bien una regla o un principio (ALEXY, 1993, p. 86-87).
\end{abstract}

As regras representam mandatos definitivos. Um conflito entre regras só poderá ser solucionado com uma cláusula de exceção ou com a eliminação de pelo menos uma das regras. ${ }^{9}$ Por sua vez, sendo os princípios mandatos de otimização, não há direito definitivo, senão um direito prima facie, ou seja, um direito que, ante uma colisão com outro direito - ou com um bem coletivo - pode ser restringido.

Não há, assim, conflitos entre princípios, mas, sim, colisões, cujo resultado não será o de eliminar um dos princípios, nem tampouco o de incluir-lhe uma cláusula de exceção. A colisão entre princípios ocasiona a necessidade de verificar, ante o caso concreto, o peso que cada princípio competente deve ter. ${ }^{10}$ Alexy afirma com propriedade que:

\begin{abstract}
(...) la solución de la colisión consiste más bien en que, teniendo en cuenta las circunstancias del caso, se establece entre los principios una relación de precedencia condicionada. La determinación de la relación de precedencia condicionada consiste en que, tomando en cuenta el caso, se indican las condiciones bajo las cuales un principio precede al otro. Bajo otras condiciones, la cuestión de la precedencia puede ser solucionada inversamente (ALEXY, 1993, p. 92).
\end{abstract}

\footnotetext{
${ }^{9}$ A cláusula de exceção não nega a regra, mas a complementa, prevendo uma situação de exceção autorizada pela mesma. Não havendo cláusula de exceção, ante um conflito de regras, pelo menos uma delas deverá ser considerada inválida, já que não se pode admitir dois juízos de dever reciprocamente contraditórios (sem ser esta contradição eliminada pela introdução de uma cláusula de exceção). Nesse caso, o problema de se decidir sobre qual regra deverá prevalecer e qual deverá ser considerada inválida pode ser resolvido por critérios de hierarquia entre elas, ou por regras tais como as que se pode extrair das expressões latinas lex posterior derotat legi priori $\mathrm{e}$ lex specialis derogat legi generali. Conforme ALEXY, 1993, p. 88. ${ }^{10}$ "Los conflictos de reglas se llevan a cabo en la dimensión de la validez; la colisión de principios - como sólo pueden entrar en colisión principios válidos tiene lugar más allá de la dimensión de la validez, en la dimensión del peso” (ALEXY, 1993, p. 89).
} 
A otimização de um princípio deve ser determinada em cada caso individual. Essa otimização deveria procurar amplificar o princípio da dignidade da pessoa humana, que permeia os padrões de direitos humanos e que se comunica com os valores que se identificam à segurança humana.

A dignidade humana só é alcançada se puder ser verificada em todas as circunstâncias, considerando seu reconhecimento constitucional, em tratados internacionais, documentos relativos à proteção de direitos humanos, ou na dimensão de valores da segurança humana. Apenas dessa maneira poder-se-á garantir a ótima aplicação do princípio da dignidade humana.

O critério que governa a relação entre um princípio normativo e os valores de segurança humana, entretanto, são menos claros que os que guiam a relação entre esse princípio e as normas constitucionais ou de regimes de direitos humanos. Nesse caso, os mecanismos de colisão e de ponderação têm sido desenvolvidos pela teoria dos direitos fundamentais. Entretanto, a otimização do princípio da dignidade humana, em sua relação com os valores contidos na segurança humana, deveriam ser investigados com maior profundidade. Parece-me que a otimização do citado princípio deve implicar sua máxima aplicação, de modo a alcançar pelo menos a situação equivalente ao que é minimamente apropriado em uma perspectiva de segurança humana. O comando de otimização seria, dessa forma, expresso em uma relação de máximo e mínimo: maximizar o princípio da dignidade humana até que esse garanta um mínimo de segurança humana.

\section{O Regime Internacional de Proteção aos Refugiados}

O sistema jurídico de proteção dos refugiados foi concretizado no contexto do processo de internacionalização dos direitos humanos - ainda que o direito dos refugiados também tenha suas bases nos primeiros precedentes do direito que regula as responsabilidades por danos causados a estrangeiros e nos esforços internacionais para a proteção de minorias nacionais (HATHAWAY, 2005, p. 75).

A Organização das Nações Unidas (ONU) foi criada em 1945, com o objetivo principal de manter a paz e segurança internacional, mas também de promover um processo de descolonização e de desenvolver e estimular o "respeito aos direitos humanos e às liberdades fundamentais de todos, sem fazer distinção por motivos de raça, sexo, idioma ou religião" (ONU, 1945, Artigo 1.3). Esse último propósito da ONU se concretizou por meio de regimes internacionais de direitos humanos, tendo como marco inicial a Declaração Universal dos Direitos Humanos (DUDH), de 1948. 
O artigo XIV da DUDH estabelece o direito de pedir e de desfrutar de asilo. ${ }^{11}$ Este dispositivo, entretanto, necessitava ser especificado por meio de um tratado internacional, o que aconteceu em 1951, com a configuração da Convenção de Genebra, que estabeleceu o Estatuto Internacional dos Refugiados.

No contexto da Segunda Guerra Mundial, multidões se deslocaram de seus lugares de origem ou de residência, principalmente na Europa. Dessa forma, a Convenção estava principalmente focada na situação dos deslocados que haviam deixado a Europa, em razão dos acontecimentos ocorridos antes do $1^{\circ}$ de janeiro de 1951, ou seja, em razão principalmente da Guerra.

O processo de descolonização e os numerosos conflitos que aconteceram no mundo, durante a Guerra Fria, promoveram o deslocamento humano forçado de milhares de pessoas que, pelos limites temporais e geográficos da Convenção de Genebra, não poderiam ser consideradas refugiados.

Assim, em 1967, os Estados criaram um Protocolo relativo ao Estatuto dos Refugiados, que suprimiu os limites temporal e geográfico da Convenção de 1951, ampliando o leque de possibilidades de aplicação do tratado.

Do ponto de vista institucional, organismos atuaram em atenção aos refugiados, desde o final da Primeira Guerra Mundial, quando foi criado o Alto Comissariado para os Refugiados. Após a II Guerra Mundial, em 1946, foi fundada a Organização Internacional para os Refugiados, depois substituída, em princípios dos anos 50, pelo Alto Comissariado das Nações Unidas para os Refugiados, órgão que funciona sob os auspícios da Organização das Nações Unidas (VILLALPANDO, sem data).

No âmbito americano, a Declaração Americana dos Direitos e Deveres do Homem (1948) e a Convenção Americana de Direitos Humanos (1969) apresentam dispositivos sobre o direito de asilo. Em 1984, Estados latino-americanos firmaram a Declaração de Cartagena, que contém um conceito de refugiado mais amplo que o da Convenção de Genebra (1951), inspirado na Convenção da Organização de Unidade Africana (OUA) sobre Aspectos Específicos dos Problemas dos Refugiados na África. Por esse conceito, além do fundado temor de perseguição pelas razões já contidas na Convenção de Genebra, também é reconhecido como refugiado aquele que deixou o país de sua nacionalidade ou residência em

\footnotetext{
${ }^{11}$ Declaração Universal dos Direitos Humanos, Artigo XIV - 1. Todo ser humano, vítima de perseguição, tem o direito de procurar e de gozar asilo em outros países. 2. Este direito não pode ser invocado em caso de perseguição legitimamente motivada por crimes de direito comum ou por atos contrários aos objetivos e princípios das Nações Unidas (ONU, 1948).
} 
razão de violação generalizada dos direitos humanos. ${ }^{12}$ A Declaração influenciou a redação do texto da lei brasileira 9.474/1997. Nos últimos anos, outras declarações e planos de ação vêm sendo firmados pelos países latino americanos, principalmente nos encontros decenais após Cartagena.

Na Convenção de Genebra de 1951 encontra-se, no artigo 33 (1) o princípio do non refoulement, cujo texto é o seguinte:

Nenhum dos Estados Contratantes expulsará ou rechaçará, de forma alguma, um
refugiado para as fronteiras dos territórios em que sua vida ou liberdade seja
ameaçada em decorrência da sua raça, religião, nacionalidade, grupo social a que
pertença ou opiniões políticas (ONU, 1951).

Efetivamente, nenhum Estado está obrigado a permitir a entrada de estrangeiros em seu território. O princípio do non refoulement representa, dessa forma, uma garantia ao refugiado de que poderá pedir e desfrutar da proteção, sob a jurisdição de outro Estado, que não o de sua nacionalidade ou domicílio, em razão da ameaça que sofre contra sua vida ou liberdade. Os Estados partes na Convenção de Genebra não podem, portanto, expulsar ou rechaçar a entrada de refugiados para as fronteiras do território onde sofre perseguições.

No entanto, o parágrafo $2^{\circ}$ do mesmo artigo 33 da Convenção de Genebra de 1951 estabelece que:

O benefício da presente disposição não poderá, todavia, ser invocado por um refugiado que por motivos sérios seja considerado um perigo para a segurança do país no qual ele se encontre ou que, tendo sido condenado definitivamente por crime ou delito particularmente grave, constitui ameaça para a comunidade do referido país (ONU, 1951).

Esse é o dispositivo em que os Estados baseiam uma justificativa, fundada na ameaça à sua segurança, para a não aplicação do princípio do non refoulement. Entretanto, o conteúdo semântico da expressão "seja considerado um perigo para a segurança do país" não foi juridicamente definido. Trata-se de uma dessas expressões de conteúdo aberto, cuja definição oscila entre a livre e ampla interpretação adotada pelos órgãos competentes do Estado receptor de solicitantes de refúgio ou a leitura restritiva, sustentada na maior liberdade do indivíduo, em razão do fundamento teleológico dos Direitos Humanos (O’BRIEN, 2011, p. 729).

${ }^{12}$ ACNUR. Declaração de Cartagena sobre Refugiados: Conclusão Terceira: “(...) la definición o concepto de refugiado recomendable para su utilización en la región es aquella que además de contener los elementos de la Convención de 1951 y el Protocolo de 1967, considere también como refugiados a las personas que han huido de sus países porque su vida, seguridad o libertad han sido amenazadas por la violencia generalizada, la agresión extranjera, los conflictos internos, la violación masiva de los derechos humanos u otras circunstancias que hayan perturbado gravemente el orden público". 
Aqui, outra vez, poder-se-ia tomar como referência o princípio da dignidade humana, em seu conteúdo otimizado, de acordo com a Teoria dos Direitos Fundamentais de Alexy, considerando-se, não a segurança do Estado, mas a segurança humana dos atores envolvidos (indivíduos dos Estados receptores, solicitantes de refúgio).

\subsection{Segurança e a regência jurídica de estrangeiros e refugiados no Brasil}

O Brasil tem um papel histórico relevante como receptor de fluxos migratórios, principalmente os destinados ao fornecimento de mão de obra para as lavouras do café, no final do século XIX e na primeira metade do século XX. Também como país de emigração, mormente em razão do ambiente ditatorial dos anos 1960 e das crises econômicas por que passou, na segunda metade do século XX. Especificamente, quanto ao recebimento de refugiados, o Brasil teve participação mais discreta. A assunção de compromissos sobre o tema acompanhou a dinâmica da política externa do país para os direitos humanos, tanto no sistema global como no sistema interamericano. O Brasil aderiu à Convenção de Genebra sobre os Refugiados em 1961, limitando sua aplicação pelas reservas temporal e geográfica, admissíveis no tratado. Aderiu ao Protocolo de Nova York em 1972, pelo qual, derrubou a reserva temporal, mantendo a geográfica, somente suprimida em 1989. Dos poucos contingentes de refugiados que recebeu do ACNUR, alguns deles tiveram dificuldades de adaptação, em razão dos contrastes culturais.

Somente após a redemocratização - e principalmente depois da promulgação da Constituição de 1988 - é que o Brasil assumiu uma postura mais consistente com relação aos direitos humanos, com consequências positivas para a proteção de refugiados. Nesse sentido, a promulgação da lei 9.474/1997 compreendia um escopo material mais amplo que o disposto na Convenção de Genebra de 1951, referente à definição de refugiado, já que incorporava também o conceito previsto na Declaração de Cartagena, de 1984. Ademais, a lei criou um órgão colegial, o Comitê Nacional para Refugiados (CONARE), inserido na estrutura do Ministério da Justiça, com as competências em matéria de reconhecimento de um potencial refugiado, em virtude de sua condição.

A legislação brasileira para os refugiados tem como referência legal os regimes internacionais e regionais de direitos humanos assumidos pelo Brasil, assim como a Carta Constitucional Brasileira, de 1988. Ainda assim, a legislação geral sobre migração é, ainda hoje, guiada por valores que eram importantes no contexto histórico-político de sua criação, 
mas que hoje não se sustentam com o mesmo vigor. ${ }^{13}$ A Lei 6.815/1980 - também denominada de Estatuto dos Estrangeiros - foi criada numa época em que o Brasil ainda se encontrava sob o regime político da ditadura militar. Além disso, o país estava inserido no contexto internacional da Guerra Fria. Isso teve implicações para o sistema legal que tomou como referências a segurança nacional e a proteção do mercado de trabalho aos brasileiros como os vetores de orientação da lei de estrangeiros no Brasil. ${ }^{14}$

Um dos fundamentos da República Federativa do Brasil é o princípio da dignidade humana. Sem uma definição precisa, seu conteúdo vem sendo estudado pela doutrina, principalmente no que concerne às relações entre o princípio e a ideia do mínimo existencial como direito fundamental (TORRES, 1995; BARCELLOS, 2011). São poucos, porém, os estudos que relacionam o princípio da dignidade humana e a segurança humana de estrangeiros no Brasil.

\section{Considerações Finais}

Os estudos de segurança têm apresentado transformações importantes, desde o século passado. Inicialmente, orientados por preocupações relacionadas à guerra, de estratégia e de geopolítica, foram assumidos e redefinidos pelas teorias de relações internacionais para, mais recentemente ganhar um escopo mais amplo, considerando não somente a segurança dos Estados, mas a segurança humana.

A segurança humana não é o mesmo que direitos humanos. Muitos aspectos daquela não estão previstos, como os direitos humanos, em documentos jurídicos de soft ou de hard law. A segurança humana pode ser tomada como um espaço de considerações para o qual devem ser dirigidos os esforços de positivação de direitos.

No que se refere a não cidadãos, as ações dos Estados têm situado o tema das imigrações como uma questão de segurança estatal, securitizando a presença de estrangeiros em seu território. Embora a abordagem de segurança humana ofereça alternativas de tratamento do tema, sua não positivação prejudica pela ausência de coerção jurídica. Nesse sentido, são necessárias investigações mais atentas às relações entre o princípio da dignidade humana - esse sim positivado no ordenamento jurídico de vários Estados ocidentais, inclusive o Brasil - e os valores que caracterizam a segurança humana de estrangeiros migrantes,

\footnotetext{
${ }^{13}$ Agora, em meados de 2015, encontra-se em tramitação no Senado Federal um projeto de nova lei de estrangeiros no Brasil. ${ }^{14}$ Lei 6.815/80 - Art. $2^{\circ}$ Na aplicação desta Lei atender-se-á precipuamente à segurança nacional, à organização institucional, aos interesses políticos, socioeconômicos e culturais do Brasil, bem assim à defesa do trabalhador nacional.
} 
principalmente refugiados, como balizadores da securitização adotada por Estados, no tratamento do tema das migrações.

Embora os desafios de segurança que o Estado brasileiro sejam menores que os de alguns Estados desenvolvidos ocidentais, também o Brasil atualmente têm sido destino de um número significativo de solicitantes de refúgio. Milhares de refugiados sírios tem chegado ao país, além do cada vez mais intenso fluxo de imigrantes provenientes de África e do Haiti. Buscando estabelecer uma agenda positiva em termos de Direitos Humanos, o Brasil tem tratado do tema da imigração tomando como referência os direitos humanos. No entanto, as ações governamentais de estímulo à integração de imigrantes (refugiados ou não), considerados os parâmetros de segurança humana, ficam aquém do que seria desejável para um país que tem como fundamento a dignidade da pessoa humana.

\section{Referências}

ACNUR. Declaration of States Parties to the 1951 Convention and or its 1967 Protocol Relating to the Status of Refugees (2001). Disponível em

<http://www.unhcr.org/3c2306cc4.html>. Acesso em 07 de julho de 2015.

ACNUR. Declaração de Cartagena sobre Refugiados (1984). Disponível em $<$ http://www.acnur.org/t3/fileadmin/scripts/doc.php?file=t3/fileadmin/Documentos/BDL/20 01/0008>. Acesso em 07 de julho de 2015.

ACNUR. State of the World's Refugees 1997: A Humanitarian Agenda. Disponível em <http://www.unhcr.org/4a4c72719.html>. Acesso em 07 de julho de 2015.

ALEXY, Robert. Teoría de los derechos fundamentales. Madrid: Centro de Estudios Constitucionales, 1993.

BARCELLOS, Ana Paula. A eficácia jurídica dos princípios constitucionais: o princípio da dignidade da pessoa humana. 3. ed. rev. e atual. Rio de Janeiro: Renovar, 2011.

BETTS, Alexander \& LOESCHER, Gil. Refugees in International Relations. Oxford: Oxford University Press, 2011.

BOULDING, Kenneth. "Peace Theory". In: SMOKER, P; DAVIES, R.; MUNSKE, B. (Orgs.). A Reader in Peace Studies. New York: Pergamon Press, 2000.

BUZAN, Barry. "Rethinking Security after the Cold War". In: Cooperation and Conflict, v. 32, n. 1, 1997. 
BUZAN, Barry. "As implicações do 11 de Setembro para o Estudo das Relações Internacionais" in Contexto Internacional. Rio de Janeiro, vol. 24, No 2, julho/dezembro 2002 (p. 233-265).

BUZAN, Barry; HANSEN, Lene. The Evolution of International Security Studies. Cambridge, Cambridge University Press, 2009.

BUZAN, Barry; WÆVER, Ole; DE WILDE, Jaap. Security: a new framework for analysis. Boulder: Lynne Rienner, 1998.

COMMISSION ON HUMAN SECURITY. Human Security Now, 2003. Disponível em <http://reliefweb.int/sites/reliefweb.int/files/resources/91BAEEDBA50C6907C1256D19006 A9353-chs-security-may03.pdf $>$. Acesso em 07 de julho de 2015.

EDWARDS, Alice. FERSTMAN, Carla. Human Security and non-citizens: Law, Policy and International Affairs. Cambridge: Cambridge University Press, 2009.

EMMERS, Ralf. Securitization. In: COLLINS, Alan. Contemporary Security Studies. Oxford: Oxford University Press, 2007.

GOODWIN-GILL, Guy. "Refugees, rights and security". In: McADAM, Jane. (ed.). Forced Migration, Human Rights and Security. Oxford: Hart Publishing, 2008.

HATHAWAY, James C. The Rights of Refugees under International Law. Cambridge (Reino Unido): Cambridge University Press, 2005.

JACKSON, Robert. SØRENSEN, Georg. Introduction to International Relations: Theories and approaches. Oxford: Oxford University Press, 2003.

LANDMAN, Todd. "Democracy and Human Security: Essential Linkages". In: AUSTIN, Reginald et all. Democracy, Conflict and Human Security. Stockholm: International Institute for Democracy and Electoral Assistance, 2006, p. 14. Disponível em: <http://www.idea.int/publications/dchs/upload/DCHS2_Inlay_Final.pdf>. Acesso em 07 de julho de 2015.

LEIKEN, Robert e BROOKE, Steven. The Quantitative Analysis of Terrorism and Immigration: An Inicial Exploration. Washington, DC: Nixon Center. Terrorism and Political Violence, N.18, 2006.

O'BRIEN, Killian. "Refugees on the High Seas: International Refugee Law Solutions to a Law of the Sea Problem". In: Goettingen Journal of International Law, No 3, 2011.

ONU. Carta das Nações Unidas (1945). Disponível em:

<http://www.un.org/es/documents/charter/chapter1.shtml>. Acesso em 07 de julho de 2015. 
ONU. Declaração Universal dos Direitos Humanos (1948). Disponível em:

<http://unicrio.org.br/img/DeclU_D_HumanosVersoInternet.pdf >. Acesso em 07 de julho de 2015.

ONU. Convenção de Genebra sobre Refugiados (1951). Disponível em

$<$ http://www.acnur.org/t3/fileadmin/Documentos/portugues/BDL/Convencao_relativa_ao_ Est atuto_dos_Refugiados.pdf?view=1>. Acesso em 07 de julho de 2015.

ONU. CS Res. 1373 (2001). Disponível em

<http://www.un.org/es/comun/docs/?symbol=S/RES/1373(2001)>. Acesso em 07 de julho de 2015.

ONU. Declaração do Milênio (2000). Disponível em:

<https://www.unric.org/html/portuguese/uninfo/DecdoMil.pdf >. Acesso em 07 de julho de 2015.

ONU (PNUD). Human Development Report. New York; Oxford: Oxford University Press, 1994.

PARIS, Roland. Human Security: paradigm shift or hot air? International Security, Vol. 26, No. 2 (Fall 2001).

TORRES, Ricardo Lobo. Os direitos humanos e a tributação: imunidades e isonomia. Rio de Janeiro: Renovar, 1995.

VILLALPANDO, Waldo. ACNUR: ¿cómo honrar um mandato? Disponível em:

$<$ http://www.acnur.org/t3/el-acnur/historia-del-acnur/acnur-como-honrar-unmandato/>. Acesso em 07 de julho de 2015.

WÆVER, Ole. "Securitization and Desecuritization”. In: LIPSCHUTZ, Ronnie D. (Ed.). On Security. New York: Columbia University Press, 1995. 